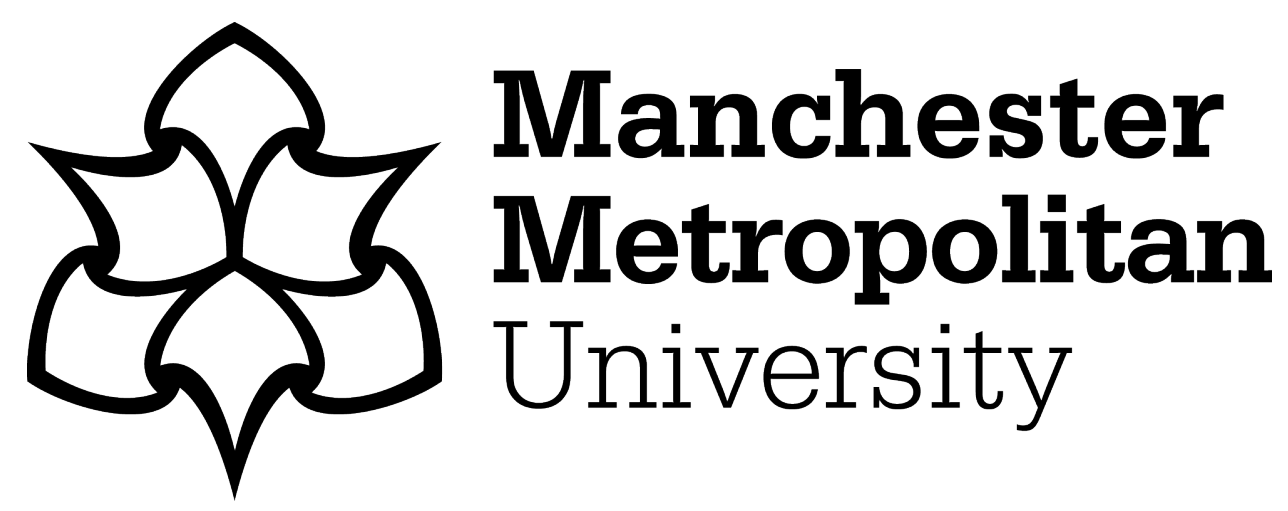

Doyle, Aidan M ORCID logoORCID: https://orcid.org/0000-0002-5800-0412, Postolache, Roxana, Shaw, David, Rothon, Roger and Tosheva, Lubomira (2019) Methane oxidation over zeolite catalysts prepared from geothermal fluids. Microporous and Mesoporous Materials, 285. pp. 56-60. ISSN 13871811

Downloaded from: https://e-space.mmu.ac.uk/622953/

Version: Accepted Version

Publisher: Elsevier BV

DOI: https://doi.org/10.1016/j.micromeso.2019.04.069

Usage rights: Creative Commons: Attribution-Noncommercial-No Derivative Works 4.0

Please cite the published version 


\section{Accepted Manuscript}

Methane oxidation over zeolite catalysts prepared from geothermal fluids

Aidan M. Doyle, Roxana Postolache, David Shaw, Roger Rothon, Lubomira Tosheva

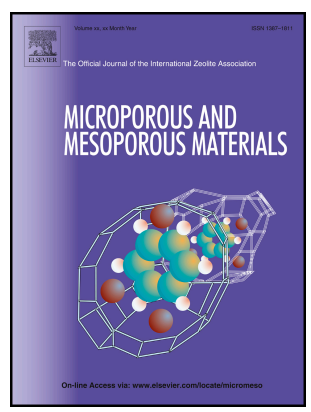

PII:

S1387-1811(19)30296-3

DOI: $\quad$ https://doi.org/10.1016/j.micromeso.2019.04.069

Reference: $\quad$ MICMAT 9473

To appear in: Microporous and Mesoporous Materials

Received Date: 1 February 2019

Revised Date: 3 April 2019

Accepted Date: 28 April 2019

Please cite this article as: A.M. Doyle, R. Postolache, D. Shaw, R. Rothon, L. Tosheva, Methane oxidation over zeolite catalysts prepared from geothermal fluids, Microporous and Mesoporous Materials (2019), doi: https://doi.org/10.1016/j.micromeso.2019.04.069.

This is a PDF file of an unedited manuscript that has been accepted for publication. As a service to our customers we are providing this early version of the manuscript. The manuscript will undergo copyediting, typesetting, and review of the resulting proof before it is published in its final form. Please note that during the production process errors may be discovered which could affect the content, and all legal disclaimers that apply to the journal pertain. 


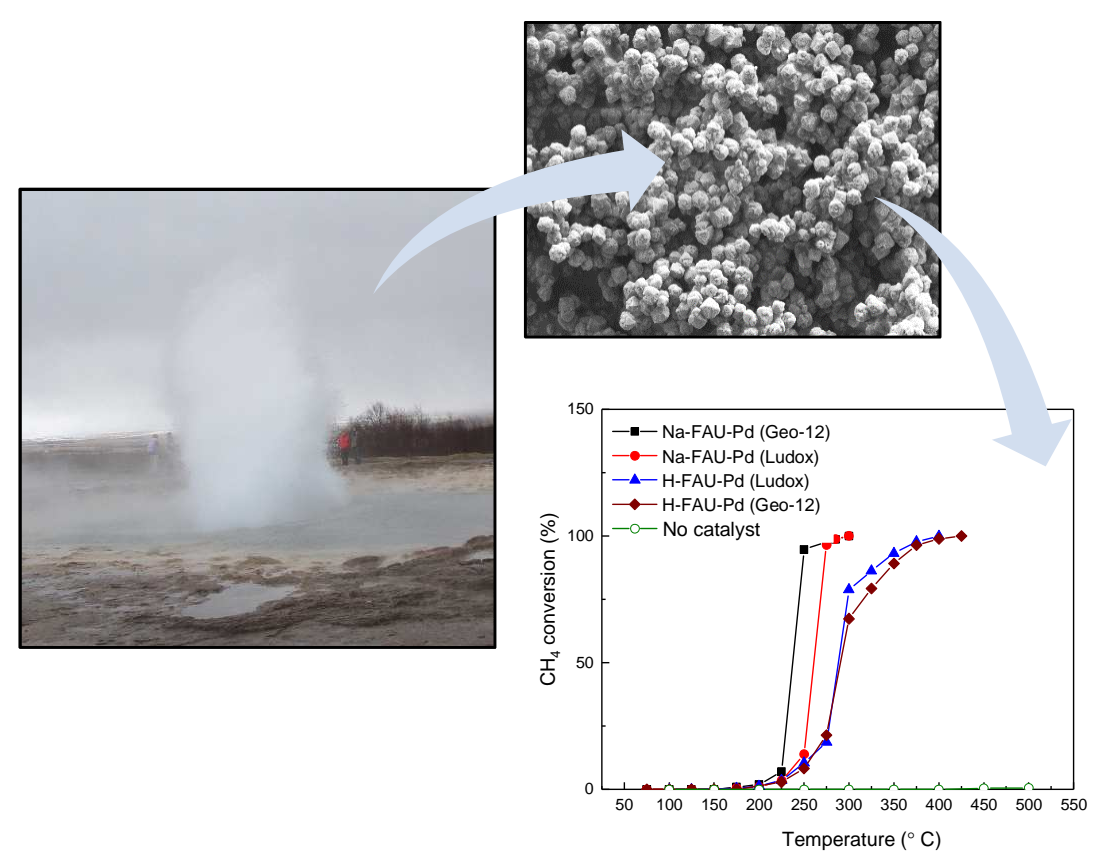




\title{
Methane oxidation over zeolite catalysts prepared from geothermal fluids
}

\section{Aidan M. Doyle*, Roxana Postolache, David Shaw, Roger Rothon, Lubomira Tosheva*}

Division of Chemistry and Environmental Science, Manchester Metropolitan University, Chester St., Manchester, M1 5GD, United Kingdom.

* Corresponding authors: a.m.doyle@mmu.ac.uk; 1 .tosheva@mmu.ac.uk

\begin{abstract}
Colloidal silica extracted from geothermal fluid was used as a reagent to produce zeolite $\mathrm{Y}$ with high purity. The characteristics of this sample were compared to a sample prepared with a conventional silica sol, namely Ludox. The two samples were treated with ammonium chloride and calcined to partially convert the samples into an $\mathrm{H}$-form. The Na-FAU and $\mathrm{H}-$ FAU zeolites were then loaded with Pd and tested as catalysts in the combustion of methane. X-ray diffraction confirmed the characteristic FAU-type framework in all samples. Experiments showed that after addition of Pd, these zeolites were active catalysts in the complete combustion of methane, where the most active catalysts were those prepared from Na-FAU. These findings support the use of low Si/Al FAU-type frameworks in model studies of engine exhaust emissions abatement. The study further shows that the silica sol extracted from geothermal fluids can be successfully utilised for zeolites synthesis.
\end{abstract}

Keywords; Methane decomposition; dual-fuel; zeolite; exhaust emissions; geothermal silica sol. 


\section{Introduction}

Methane fuel can be sourced from natural gas or biological processes, and is used widely for heating and electricity generation. The widespread application of shale bed fracking has greatly increased the amount of available methane and it is predicted that the USA has reserves to last at least a century at current usage [1]. Biomethane is increasingly being extracted from waste e.g. municipal landfill sites, and renewably using algal biomass [2]. In addition to diesel, dual-fuel engines use an alternative energy source in a conventional compression ignition engine [3]. During dual-fuel operation the engine is fuelled by two fuels simultaneously, whereby combustion of the secondary fuel occurs alongside the conventional compression-induced ignition of diesel [4]. When methane is used as the secondary fuel, the operating costs of transportation are reduced [5]. Methane has the highest hydrogen to carbon ratio of any hydrocarbon, 4:1 versus $\leq 2: 1$ for diesel, so produces less carbon dioxide than the equivalent diesel engine, making dual-fuel a realistic possibility in the decarbonisation of transport systems, particularly for heavy goods vehicles. The main obstacle relates to the concentration of unburned methane in exhaust gasses that is often greater than that allowed by current emissions legislation (developed for single fuel engines) [6,7]. As a result, there has been an intensive research effort to decompose methane in exhaust emissions $[8,9]$. To this end, methane oxidation has been studied using a range of reactions, such as steam reforming, partial oxidation, autothermal reforming, and dry reforming of methane (DRM) with carbon dioxide [10-14].

Complete methane oxidation occurs under stoichiometric and/or excess oxygen conditions to produce carbon dioxide and water. Pd nanoparticles supported on high surface area aluminosilicate zeolites are active catalysts for this reaction [15-18]. FAU-type zeolite is classified by its $\mathrm{Si} / \mathrm{Al}$ ratio as either type $\mathrm{X}(1<\mathrm{Si} / \mathrm{Al}<1.5)$ or $\mathrm{Y}(\mathrm{Si} / \mathrm{Al} \geq 1.5)$. When used as a catalyst support, FAU is usually in the form of zeolite $\mathrm{Y}$ with $\mathrm{Si} / \mathrm{Al}$ ratios orders of 
magnitude higher than 1.5. There are far fewer reports of using low Si/Al FAU-type zeolites as heterogeneous catalysts. Zeolites have been prepared using waste and/or naturally occurring materials e.g. amorphous silica has been extracted from rice husk or diatomite and hydrothermally treated to form zeolite [19-21]. Here, colloidal silica extracted from geothermal fluid in the Taupo Volcanic Zone, New Zealand, is used for the first time as a reagent to prepare zeolite and, following addition of $\mathrm{Pd}$, was tested in the complete oxidation of methane. The zeolite characteristics were broadly similar to those using Ludox SM, a commercially available colloidal silica source often used for the preparation of sub-micron sized zeolites [22]. Our results show that the prepared materials were active catalysts, which confirms that a freely available natural silica source, with almost limitless supply, can be used to prepare zeolite catalysts that are effective in decreasing dual-fuel engine exhaust emissions. Furthermore, the findings support the application of low Si/Al FAU-type frameworks in model studies of engine exhaust emissions abatement.

\section{Experimental}

\subsection{Materials}

Geosol 12 colloidal amorphous silica with a $12 \mathrm{~nm}$ mean particle size (30 wt $\%$ water suspension stabilised by sodium hydroxide, Geo 40 Limited); Ludox SM colloidal silica (30 wt\% water suspension containing sodium stabilising counterion, Sigma-Aldrich); sodium hydroxide $(\mathrm{NaOH})$ pellets (anhydrous, Sigma-Aldrich); sodium aluminate $\left(\mathrm{NaAlO}_{2}\right)(50.5 \%$ $\mathrm{Al}_{2} \mathrm{O}_{3}, 44.1 \% \mathrm{Na}_{2} \mathrm{O}$, Fisher Scientific); ammonium chloride $\left(\mathrm{NH}_{4} \mathrm{Cl}\right)$ (Sigma-Aldrich); palladium(II) nitrate dihydrate $\left(\mathrm{Pd}(\mathrm{II})\left(\mathrm{NO}_{3}\right)_{2} \cdot 2 \mathrm{H}_{2} \mathrm{O}\right)$ (Sigma-Aldrich); ammonium hydroxide $\left(28 \% \mathrm{NH}_{3}\right.$, Alfa Aesar).

\subsection{Catalyst synthesis}


The FAU-type zeolites were prepared from a synthesis solution with the following molar composition: $8.6 \mathrm{Na}_{2} \mathrm{O}: 1.0 \mathrm{Al}_{2} \mathrm{O}_{3}: 16.7 \mathrm{SiO}_{2}: 435 \mathrm{H}_{2} \mathrm{O} .4 .90 \mathrm{~g}$ of $\mathrm{NaOH}$ were mixed with distilled water in a beaker and stirred for $10 \mathrm{~min}$ followed by the addition of $1.20 \mathrm{~g}$ of $\mathrm{NaAlO}_{2}$, and, after additional stirring for $5 \mathrm{~min}, 20 \mathrm{~g}$ of colloidal silica was added. The mixture was stirred for $1 \mathrm{~h}$ and transferred to a polypropylene reactor. The mixture was aged at $30{ }^{\circ} \mathrm{C}$ for $20 \mathrm{~h}$ and then hydrothermally treated at $90{ }^{\circ} \mathrm{C}$ for $24 \mathrm{~h} \mathrm{[23].} \mathrm{After} \mathrm{the} \mathrm{synthesis,}$ the zeolites were purified by three-times centrifugation and redispersion in distilled water and dried at $90{ }^{\circ} \mathrm{C}$ overnight. The zeolites prepared with the two colloidal silica sources were labelled as Na-FAU (Geo-12) and Na-FAU (Ludox), respectively. Samples were also prepared, in which the as-made zeolites were partially converted into an $\mathrm{H}^{+}$form. For these experiments, $1 \mathrm{~g}$ of corresponding Na-zeolites was mixed with $100 \mathrm{~g}$ of $0.05 \mathrm{M} \mathrm{NH}_{4} \mathrm{Cl}$ solution in a beaker and stirred for $24 \mathrm{~h}$. The zeolites were then purified by four times centrifugation and redispersion in distilled water, dried at $90{ }^{\circ} \mathrm{C}$ overnight, ground in a mortar, and calcined at $500{ }^{\circ} \mathrm{C}$ for $4 \mathrm{~h}$ using a heating rate $10{ }^{\circ} \mathrm{C} \mathrm{min}^{-1}$. These samples were labelled as H-FAU (Geo-12) and H-FAU (Ludox), correspondingly.

Pd-loaded zeolite samples were prepared as follows: $0.02 \mathrm{M}$ Pd solutions were prepared in 25 $\mathrm{ml}$ volumetric flasks; the $\mathrm{pH}$ of the solutions was adjusted with ammonium hydroxide to a $\mathrm{pH}$ range of 10-12. $25 \mathrm{mls}$ of $\mathrm{Pd}$ solution was added to $0.8 \mathrm{~g}$ of each zeolite sample in a beaker, sonicated in an ultrasonic bath for $45 \mathrm{~min}$ and then stirred overnight. The samples were recovered by filtration, washed with copious amounts of distilled water, dried and calcined at $550{ }^{\circ} \mathrm{C}$ for $4 \mathrm{~h}$. Corresponding samples were labelled as Na-FAU-Pd (Geo-12), Na-FAU-Pd (Ludox), H-FAU-Pd (Geo-12) and H-FAU-Pd (Ludox).

\subsection{Characterisation}


X-Ray diffraction (XRD) was conducted in ambient conditions using a Panalytical X'Pert Powder diffractometer with $\mathrm{Cu} \mathrm{K} \alpha$ radiation $(\lambda=1.5406 \AA)$. All powder diffraction patterns were recorded from 4 to $120^{\circ} 2 \theta$ with step size $0.013^{\circ}$ and step time $50 \mathrm{~s}$, using an X-ray tube operated at $40 \mathrm{kV}$ and $30 \mathrm{~mA}$ with fixed $14^{\circ}$ anti-scatter slit. A Rigaku NEX-CG XRF spectrometer was used for elemental analysis using the loose powder method under vacuum. Nitrogen adsorption/desorption measurements were carried out using a Micromeritics ASAP 2020 surface area analyser at $-196^{\circ} \mathrm{C}$. Samples were degassed under vacuum $\left(\mathrm{p}<10^{-5}\right.$ mbar $)$ for $12 \mathrm{~h}$ at $300{ }^{\circ} \mathrm{C}$ prior to analysis. BET surface areas of the samples were calculated in the relative pressure range $0.05-0.30$. Total pore volumes were calculated from the volume adsorbed at a relative pressure of 0.99 after conversion to the volume of liquid adsorbate. Micropore volumes were determined by the t-plot volumes. Microscopic images were recorded using a Carl Zeiss Ltd Supra 40VP scanning electron microscope (SEM). Samples were coated with gold prior to analysis.

\subsection{Catalytic tests}

The catalyst activity of each sample was studied in a quartz fixed bed reactor, shown in Fig. 1, placed inside a temperature controlled furnace (Carbolite type 3216, Tempatron, PID500/110/330). $0.2 \mathrm{~g}$ of catalyst was taken directly from the calcination furnace and immediately placed in a quartz tube (10 $\mathrm{mm}$ diameter, $1 \mathrm{~mm}$ thickness $)$ between quartz wool plugs. A feed mixture of $50 \mathrm{ml} \mathrm{min}^{-1}$ comprising $\mathrm{CH}_{4}: \mathrm{O}_{2}: \mathrm{He}$ equal to 5:10:35 was used in all catalytic tests. Gases were supplied from lecture bottles (CKGAS filled to 200 Bar at $15{ }^{\circ} \mathrm{C}$ ) and regulated using single stage CONCOA 302 series gas regulators. The flow of each gas was maintained using Bronkhorst UK model F-201CV mass flow controllers. The reaction products were monitored by a Hewlett Packard 5890 series II gas chromatograph equipped with a Carboxen 1010 plot fused silica capillary column (30 m x $0.53 \mathrm{~mm}$ ) connected via a 6- 
way gas sampling valve to a thermal conductivity detector. Measurements were recorded at $25{ }^{\circ} \mathrm{C}$ intervals (after holding at that temperature for 5 mins) starting at $75{ }^{\circ} \mathrm{C}$ using a heating rate of $10{ }^{\circ} \mathrm{C} \min ^{-1}$.

\section{Results \& discussion}

\subsection{Characterisation}

XRD analysis of the samples prepared with the two silica sources, Fig. 2, indicated that both samples consisted of crystalline FAU-type framework for the as-made Na-FAU (Ludox) and Na-FAU (Geo-12). The Ludox-based synthesis is a well-established preparation for zeolites; its similarity, therefore, in both diffraction pattern and peak intensities to the material prepared using Geo-12 validates both the use of this geothermal fluid extract as a reagent and the method used in this paper to prepare FAU-type zeolite. A reduction in FAU-type XRD intensities is observed following the partial removal of $\mathrm{Na}^{+}$and addition of $\mathrm{Pd}$, evidenced by the reflections indicated in Fig. 2. However, the results clearly confirm that the Pd catalysts retain the characteristic FAU-type structure. SEM confirmed the FAU-type material with its typical octahedral morphology (Fig. 3). The samples contained agglomerated sub-micron sized particles. No impurities of other crystalline phases or presence of amorphous material were observed in the SEM images.

$\mathrm{XRF}$ analysis in Table 1 shows that the $\mathrm{Si} / \mathrm{Al}$ ratios of the as-made $\mathrm{Na}^{+}$forms were 1.94 and 1.96 for preparations with Ludox and Geo-12, respectively, which varied marginally after Pd addition. The $\mathrm{Na}^{+}$content reduced following addition of Pd to both as-made zeolites, particularly so after $\mathrm{NH}_{4} \mathrm{Cl}$ exchange; from $13.5 \mathrm{wt} \%$ to $4.40 \mathrm{wt} \%$ for Geo-12, and from 12.6 wt $\%$ to $4.06 \mathrm{wt} \%$ for Ludox. All catalysts presented here can be classified as 'low' $\mathrm{Si} / \mathrm{Al}$ ratio zeolite Y. Further, the textural characteristics of the samples provided in Table 1 indicated that the surface areas reduced slightly as a result of $\mathrm{NH}_{4} \mathrm{Cl}$ treatment (surface areas of $\mathrm{H}$-FAU 
(Ludox) and H-FAU (Geo-12) were 587 and $561 \mathrm{~m}^{2} \mathrm{~g}^{-1}$, respectively, surface area, only, determined for these two samples) and Pd introduction to Na-FAU samples. The reduced micropore volume in the two Na-FAU-Pd samples, accompanied with reduction in the intensity of the XRD peaks (not shown) suggests a certain degree of amorphisation of the FAU-type material. The surface areas and micropore volumes of the Pd-loaded zeolites obtained from H-FAU samples were substantially lower, which could be due to the introduction of defects during the $\mathrm{NH}_{4} \mathrm{Cl}$ treatment and subsequent calcination, making the zeolite framework vulnerable during the Pd treatment. It should be noted that preliminary experiments to convert the zeolites into an $\mathrm{H}$-form were performed with $2 \mathrm{M} \mathrm{NH}_{4} \mathrm{Cl}$ solution [24]. The conversion procedure resulted in complete amorphisation of both zeolites independently of the silica sol used. These preliminary results indicate that the $\mathrm{NH}_{4} \mathrm{Cl}$ treatment is the main reason for the observed substantial reduction of the surface areas and pore volumes of H-FAU-Pd materials. The pore volumes of samples prepared with Ludox were higher, which could be due to smaller particle sizes of this sample (Fig. 2).

Nitrogen adsorption desorption isotherms of the Na-FAU-Pd and the H-FAU-Pd zeolites are shown in Fig. 4. The isotherms are of Type I classification in agreement with the XRD results. The retention of the shape of the isotherms, despite the substantial reduction in the micropore volumes for the latter samples, suggests the formation of a low surface area dense amorphous material in H-FAU-Pd samples. Hysteresis loops caused by intercrystalline porosity are present in all isotherms, however the isotherms do not appear to plateau at high relative pressures, as one would expect for a Type IV classification. Such characteristics have been attributed to Type IIb isotherms by Rouquerol et al. [25]. The shape of the hysteresis loop changes from $\mathrm{H} 1$ in Na-FAU-Pd, which is characteristic of agglomerates or compacts of spheroidal particles of fairly uniform size, to $\mathrm{H} 3$ in H-FAU-Pd, suggesting the presence of aggregated powders in the latter [26]. The latter is supported by corresponding BJH pore size 
distributions (inserts in Fig. 2). The authors acknowledge that assigning porosity characteristics at relative pressures approaching unity is prone to error so the discussion here is given tentatively.

\subsection{Catalyst testing}

The complete oxidation of methane is used both as a test reaction and to determine the suitability of the zeolites prepared in this study as precious metal catalyst supports in engine exhaust emissions treatment. Carbon monoxide was not detected in any of the experiments. All catalysts containing Pd were active; the results are shown as light-off curves in Fig. 5 and the temperatures required for $10 \%$ and $50 \%$ conversion, $\mathrm{T}_{10}$ and $\mathrm{T}_{50}$, in Table 2 . Overall, the $\mathrm{Na}^{+}$forms of the catalysts were more active than the $\mathrm{H}^{+}$forms. The highest reactivity was measured for Na-FAU-Pd (Geo 12), which gave $\mathrm{T}_{10}$ and $\mathrm{T}_{50}$ values $226{ }^{\circ} \mathrm{C}$ and $237^{\circ} \mathrm{C}$, respectively. The fact that Na-FAU-Pd (Geo 12) was more active than Na-FAU-Pd (Ludox) $\left(241{ }^{\circ} \mathrm{C}\right.$ and $261{ }^{\circ} \mathrm{C}$ ) confirms that the geothermal colloidal silica has comparably suitable properties to those of a conventional reagent, Ludox, in the preparation of zeolite. The HFAU-Pd (Geo 12) and H-FAU-Pd (Ludox) catalysts had broadly similar activities, whereby $\mathrm{T}_{10}$ and $\mathrm{T}_{50}$ varied by no more than $5^{\circ} \mathrm{C}$ from each other.

It is interesting to note that in addition to the higher activities of the $\mathrm{Na}^{+}$catalysts, there is also a more rapid light-off for these catalysts, as seen by the gradient of the conversion increase with temperature. This effect can be quantified by examining the difference between $\mathrm{T}_{10}$ and $\mathrm{T}_{50}$ values; the greater the rate of conversion increase the lower this temperature difference. The $\mathrm{Na}^{+}$catalysts had maximum $\mathrm{T}_{50}-\mathrm{T}_{10}$ values of $20^{\circ} \mathrm{C}$, versus $40{ }^{\circ} \mathrm{C}$ for the $\mathrm{H}^{+}$ forms, and the lowest value overall, $11^{\circ} \mathrm{C}$, was recorded for the preparation using the geothermal source. There is also an important difference in the shape of the light-off curves: while the $\mathrm{Na}^{+}$catalysts approach $100 \%$ conversion almost immediately after light-off, the 
conversion reaches $67 \%$ for H-FAU-Pd (Geo 12) and 79\% for H-FAU-Pd (Ludox) at $300{ }^{\circ} \mathrm{C}$, after which there is a relatively gradual conversion increase towards $100 \%$. The reduced activities of the catalysts in $\mathrm{H}^{+}$form are not attributed solely to the lower quantity of $\mathrm{Na}^{+}$, as studies have shown that that $\mathrm{Na}^{+}$does not promote diesel/methane oxidation [27, 28]. It is therefore the addition of $\mathrm{Pd}$ and/or additional calcination step to form $\mathrm{H}^{+}$that is attributed to the partial reduction in catalyst crystallinity and porosity, which manifests as a decrease in catalytic activity (although these catalysts still retain activity). Thermodynamic data, calculated up to $30 \%$ conversion, showed activation energies in the range $71.1-90.3 \mathrm{~kJ} \mathrm{~mol}^{-1}$ : these values are comparable to similar studies for methane oxidation e.g. in a recent study of Pd-MOR catalysts the activation energies were calculated to be $75-84 \mathrm{~kJ} \mathrm{~mol}^{-1}$ [15].

\section{Conclusions}

Silica sol extracted from geothermal fluid extract was used as a silica source for the synthesis of low $\mathrm{Si} / \mathrm{Al}$ zeolite $\mathrm{Y}$. The similarity in the characteristics of this sample to one prepared with a conventional silica sol, Ludox, demonstrated that this natural silica source can be successfully used for the synthesis of zeolites with high purity. The zeolite Y prepared from the two silica sources was loaded with Pd, both as-made Na-samples and after partial conversion to H-zeolites. Na-FAU-Pd samples showed slight decreases in surface areas and micropore volumes as a result of the Pd loading, whereas the reduction was substantial for $\mathrm{H}$ FAU-Pd samples, which was attributed to the additional synthesis steps involved in the preparation of these samples. All zeolites containing Pd were catalytically active in the oxidative decomposition of methane, whereby the highest activities were recorded for catalysts containing Na. Overall, the findings show that a natural silica source, with almost limitless supply, can be used as a reagent to prepare zeolite catalysts that are effective in decreasing dual-fuel engine exhaust emissions. This study is particularly interesting in that it 
makes use of a freely available natural resource that can contribute to the decarbonisation of heavy goods transportation.

\section{Acknowledgments}

Roxana Postolache is grateful to Erasmus+ and Manchester Metropolitan University for financial assistance.

\section{References}

[1] U. Izquierdo, V.L. Barrio, J. Requies, J.F. Cambra, M.B. Güemez, P.L. Arias, International Journal of Hydrogen Energy, 38 (2013) 7623-7631.

https://doi.org/10.1016/j.ijhydene.2012.09.107

[2] X. Shan, Y. Qian, L. Zhu, X. Lu, Fuel, 181 (2016) 1050-1057.

https://doi.org/10.1016/j.fuel.2016.04.132

[3] C. Abagnale, M.C. Cameretti, L. De Simio, M. Gambino, S. Iannaccone, R. Tuccillo, Thermal Engineering, 65 (2014) 403-417.

[4] J. Benajes, A. García, J. Monsalve-Serrano, I. Balloul, G. Pradel, Energy Conversion and Management, 123 (2016) 381-391. https://doi.org/10.1016/j.enconman.2016.06.059

[5] J. Klimstra, 11 - Fuel flexibility with dual-fuel engines A2 - Oakey, John, in: Fuel Flexible Energy Generation, Woodhead Publishing, Boston, 2016, pp. 293-304.

[6] B. Bharathiraja, T. Sudharsanaa, A. Bharghavi, J. Jayamuthunagai, R. Praveenkumar, Fuel, 185 (2016) 810-828. https://doi.org/10.1016/j.fuel.2016.08.030

[7] M. Crippa, G. Janssens-Maenhout, D. Guizzardi, S. Galmarini, Journal of Environmental Management, 183, Part 3 (2016) 959-971. https://doi.org/10.1016/j.jenvman.2016.09.068 
[8] Y. Karagöz, T. Sandalcı, U.O. Koylu, A.S. Dalkılıç, S. Wongwises, Advances in Mechanical Engineering 8 (2016) 1-13. https://doi.org/10.1177/1687814016643228

[9] B. Challen, R. Baranescu, Diesel Engine Reference Book, Society of Automotive Engineers, 1999.

[10] R. Horn, R. Schlögl, Catalysis Letters, 145 (2015) 23-39.

https://doi.org/10.1007/s10562-014-1417-z

[11] B. Christian Enger, R. Lødeng, A. Holmen, Applied Catalysis A: General, 346 (2008) 127. https://doi.org/10.1016/j.apcata.2008.05.018

[12] P. Gélin, M. Primet, Applied Catalysis B: Environmental, 39 (2002) 1-37.

https://doi.org/10.1016/S0926-3373(02)00076-0

[13] J.H. Lunsford, Catalysis Today, 63 (2000) 165-174. https://doi.org/10.1016/S0920$\underline{5861(00) 00456-9}$

[14] J. Kamieniak, P.J. Kelly, C.E. Banks, A.M. Doyle, Fuel 208 (2017) 314-320. https://doi.org/10.1016/j.fuel.2017.07.012

[15] A.W. Petrov, D. Ferri, F. Krumeich, M. Nachtegaal, J.A. van Bokhoven, O. Kröcher, Nature Communications 9:2545 (2018). https://doi.org/10.1038/s41467-018-04748-x

[16] R. Gholami, M. Alyani, K.J. Smith, Catalysts 5 (2015) 561-594.

https://doi.org/10.3390/catal5020561

[17] Y. Li, J.N. Armor, Appl. Catal. B: Environ. 3 (1994) 275-282.

https://doi.org/10.1016/0926-3373(94)0006Z-H

[18] C. Montes de Correa, A.L. Villa, Appl. Catal. B: Environ. 10 (1996) 313-323. https://doi.org/10.1016/S0926-3373(96)00039-2

[19] A.V. Rawtani, M.S. Rao, K.V.G.K. Gokhale, Ind. Eng. Chem. Res., 28(9) (1989) 14111414. https://doi.org/10.1021/ie00093a021 
[20] H.Katsuki, S. Furuta, T. Watari, S. Komarneni, Microporous Mesoporous Mater., 86 (2005) 145-151. https://doi.org/10.1016/j.micromeso.2005.07.010

[21] G. Garcia, E. Cardenas, S. Cabrera, J. Hedlund, J. Mouzon, Microporous Mesoporous Mater., 219 (2016) 29-37. https://doi.org/10.1016/j.micromeso.2015.07.015

[22] B.J. Schoeman, J. Sterte, J.-E. Otterstedt, Zeolites, 14 (1994) 110-116. https://doi.org/10.1016/0144-2449(94)90004-3

[23] D. Reinoso, M. Adrover, M. Pedernera, Ultrason. Sonochem. 42 (2018) 303-309. https://doi.org/10.1016/j.ultsonch.2017.11.034

[24] A. M. Doyle, Z. T. Alismaeel, T. M. Albayati, A. S. Abbas, Fuel 199 (2017) 394-402. http://dx.doi.org/10.1016/j.fuel.2017.02.098

[25] F. Rouquerol, J. Rouquerol, Kenneth Sing, Adsorption by Powders and Porous Solids. Principles, Methodology and Applications, Academic Press, London, 1999, p. 441.

[26] K. S. W. Sing, D. H. Everett, R. A. W. Haul, L. Moscou, R. A. Pierotti, J. Rouquerol, T. Siemieniewska, Pure Appl. Chem., 57 (1985) 603-619. https://doi.org/10.1002/9783527610044.hetcat0065 [27] X. Auvray A. Lindholm M. Milh L. Olsson, Catalysis Today, 299 (2018) 212-218. https://doi.org/10.1016/j.cattod.2017.05.066 [28] Y. Xie, M.E. Galvez, A. Matynia, P. Da Costa, Clean Technologies and Environmental Policy, 20 (2018) 715-725. https://doi.org/10.1007/s10098-017-1412-3 
Table 1: $\mathrm{Si} / \mathrm{Al}$ ratio, $\mathrm{Na}$ and $\mathrm{Pd}$ wt $\%$ as determined by $\mathrm{XRF}$, and textural characteristics determined from nitrogen adsorption measurements at $-196{ }^{\circ} \mathrm{C}$ : BET surface areas $\left(\mathrm{S}_{\mathrm{BET}}\right)$, micropore volumes $\left(\mathrm{V}_{\mu}\right)$ and total pore volumes $\left({ }_{\text {total }}\right)$.

\begin{tabular}{ccccccc}
\hline Sample & Si/Al & $\begin{array}{c}\mathrm{Na} \\
(\mathrm{wt} \%)\end{array}$ & $\begin{array}{c}\mathrm{Pd} \\
(\mathrm{wt} \%)\end{array}$ & $\begin{array}{c}\mathrm{S}_{\mathrm{BET}} \\
\left(\mathrm{m}^{2} \mathrm{~g}^{-1}\right)\end{array}$ & $\begin{array}{c}\mathrm{V}_{\mu} \\
\left(\mathrm{cm}^{3} \mathrm{~g}^{-1}\right)\end{array}$ & $\begin{array}{c}\mathrm{V}_{\text {total }} \\
\left(\mathrm{cm}^{3} \mathrm{~g}^{-1}\right)\end{array}$ \\
\hline Na-FAU (Geo-12) & 1.96 & 13.5 & - & 652 & 0.28 & 0.74 \\
Na-FAU (Ludox) & 1.94 & 12.6 & - & 672 & 0.30 & 0.85 \\
H-FAU (Geo-12) & 2.11 & 6.87 & - & 561 & $\mathrm{n} . \mathrm{m}$. & $\mathrm{n} . \mathrm{m}$. \\
H-FAU(Ludox) & 1.91 & 7.40 & - & 587 & $\mathrm{n} . \mathrm{m}$. & $\mathrm{n} . \mathrm{m}$. \\
Na-FAU-Pd (Geo-12) & 2.13 & 8.24 & 5.65 & 556 & 0.24 & 0.56 \\
Na-FAU-Pd (Ludox) & 2.05 & 7.75 & 6.21 & 612 & 0.24 & 0.57 \\
H-FAU-Pd (Geo-12) & 1.92 & 4.40 & 2.30 & 321 & 0.09 & 0.32 \\
H-FAU-Pd (Ludox) & 2.01 & 4.06 & 5.25 & 312 & 0.11 & 0.39 \\
\hline
\end{tabular}

n.m. - not measured 
Table 2: $\mathrm{T}_{10}, \mathrm{~T}_{50}$ and thermodynamic data for methane oxidation.

\begin{tabular}{ccccc}
\hline & $\mathrm{T}_{10}\left({ }^{\circ} \mathrm{C}\right)$ & $\mathrm{T}_{50}\left({ }^{\circ} \mathrm{C}\right)$ & $\mathrm{T}_{50}-\mathrm{T}_{10}\left({ }^{\circ} \mathrm{C}\right)$ & $\mathrm{E}_{\mathrm{a}}\left(\mathrm{kJ} \mathrm{mol}^{-1}\right)$ \\
\hline Na-FAU-Pd (Geo 12) & 226 & 237 & 11 & 71.1 \\
Na-FAU-Pd (Ludox) & 241 & 261 & 20 & 82.6 \\
H-FAU-Pd (Geo 12) & 253 & 290 & 37 & 90.3 \\
H-FAU-Pd (Ludox) & 248 & 288 & 40 & 76.5 \\
\hline
\end{tabular}




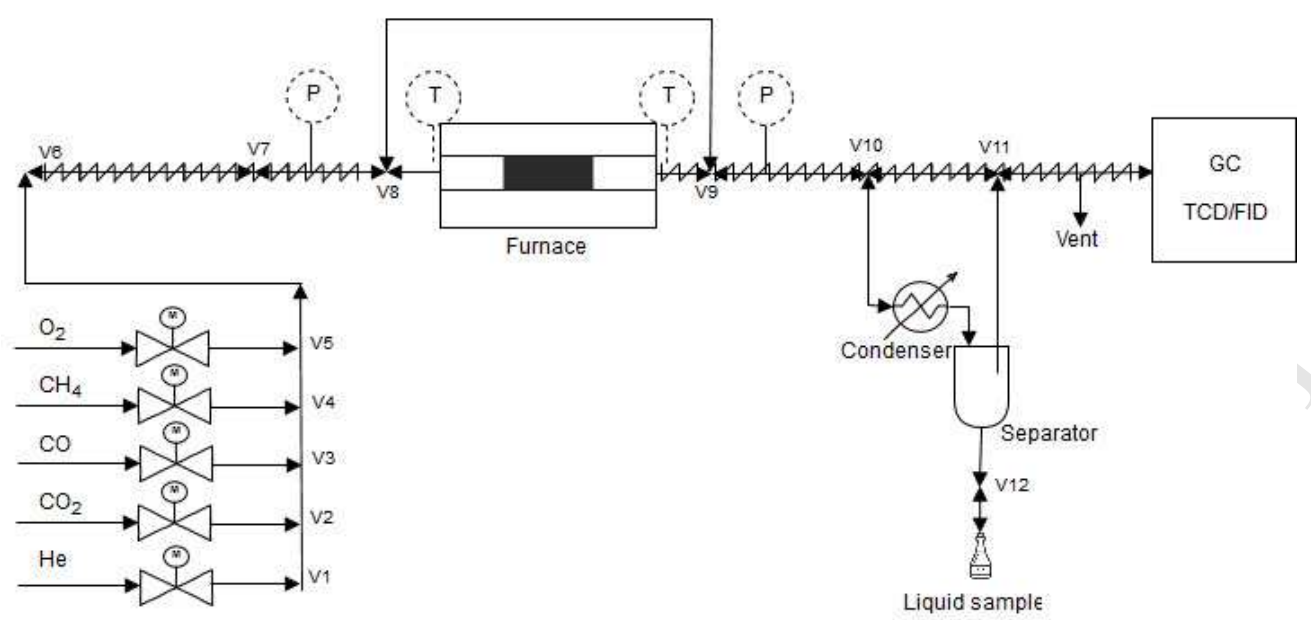

Fig. 1: PFD of catalyst testing rig. 


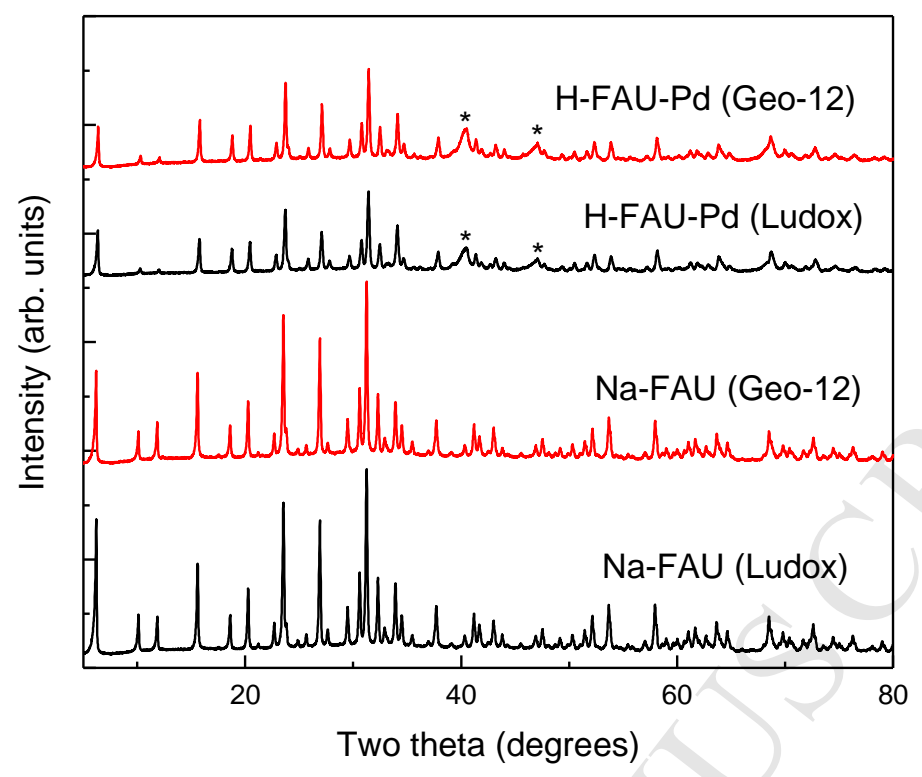

Fig. 2: XRD patterns of FAU zeolites prepared with Ludox and Geo-12: as-made (Na-FAU) and after Pd impregnation of H-FAU samples (Pd-H-FAU): Pd peaks are indicated with an *. 


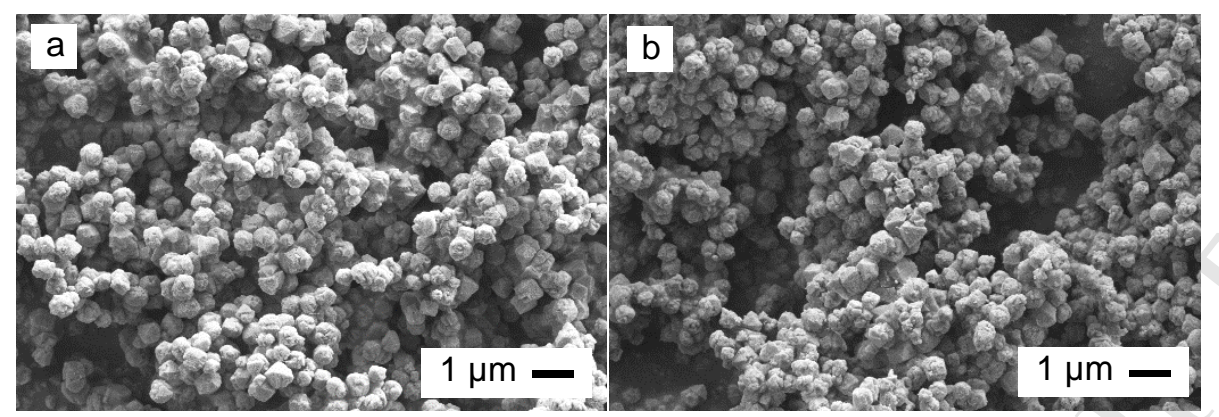

Fig. 3: SEM images of FAU-type zeolites prepared with (a) Geo-12 and (b) Ludox. 

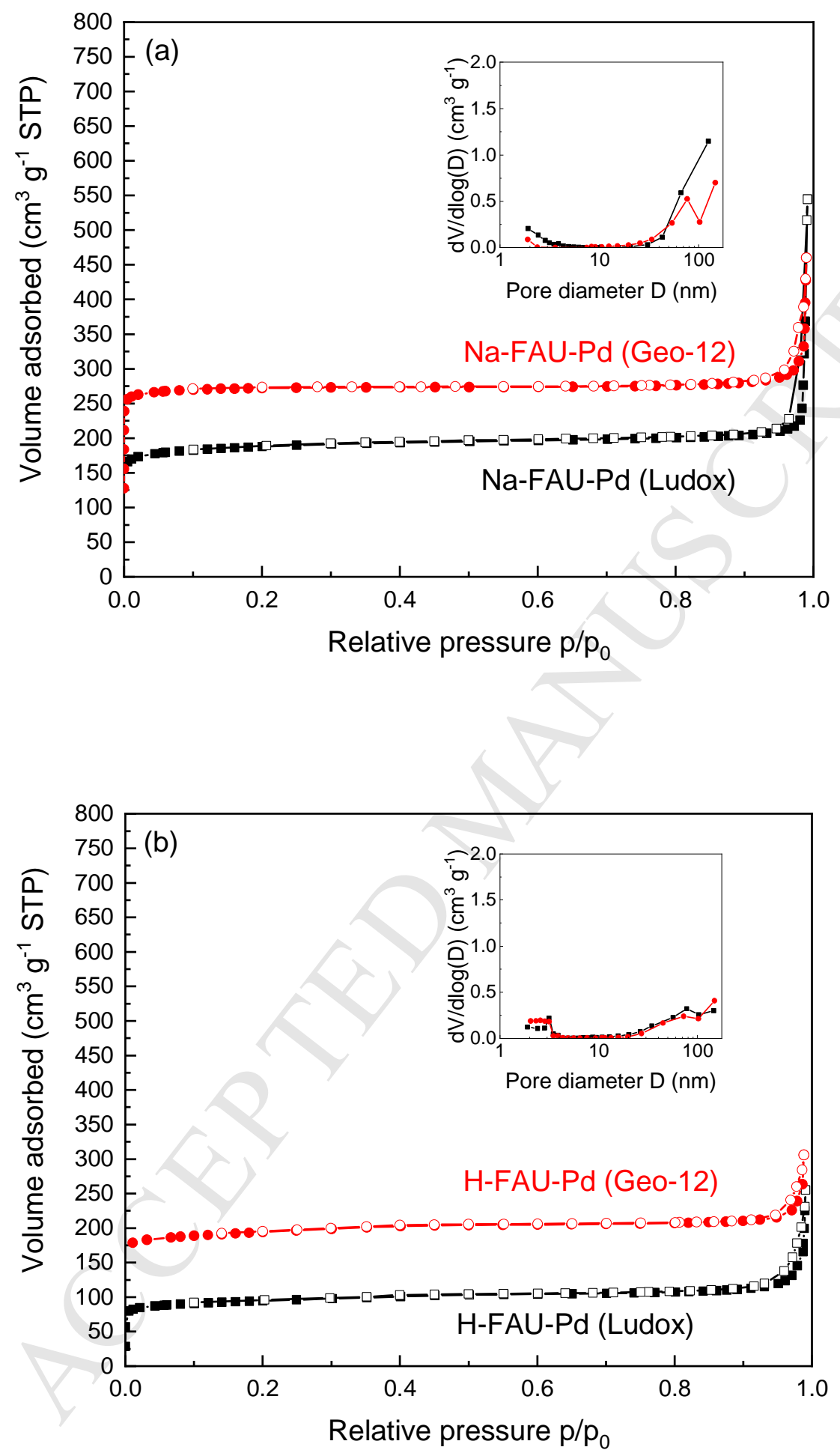

Fig. 4: Nitrogen adsorption desorption isotherms of (a) Na-FAU-Pd and (b) H-FAU-Pd zeolites prepared with Ludox and Geo-12. Closed symbols, adsorption; open symbols, desorption. The isotherms of Na-FAU-Pd (Geo-12) and H-FAU-Pd (Geo-12) have been shifted by 100 along the yaxis for clarity. The inserts show corresponding BJH pore size distributions (desorption branch). 


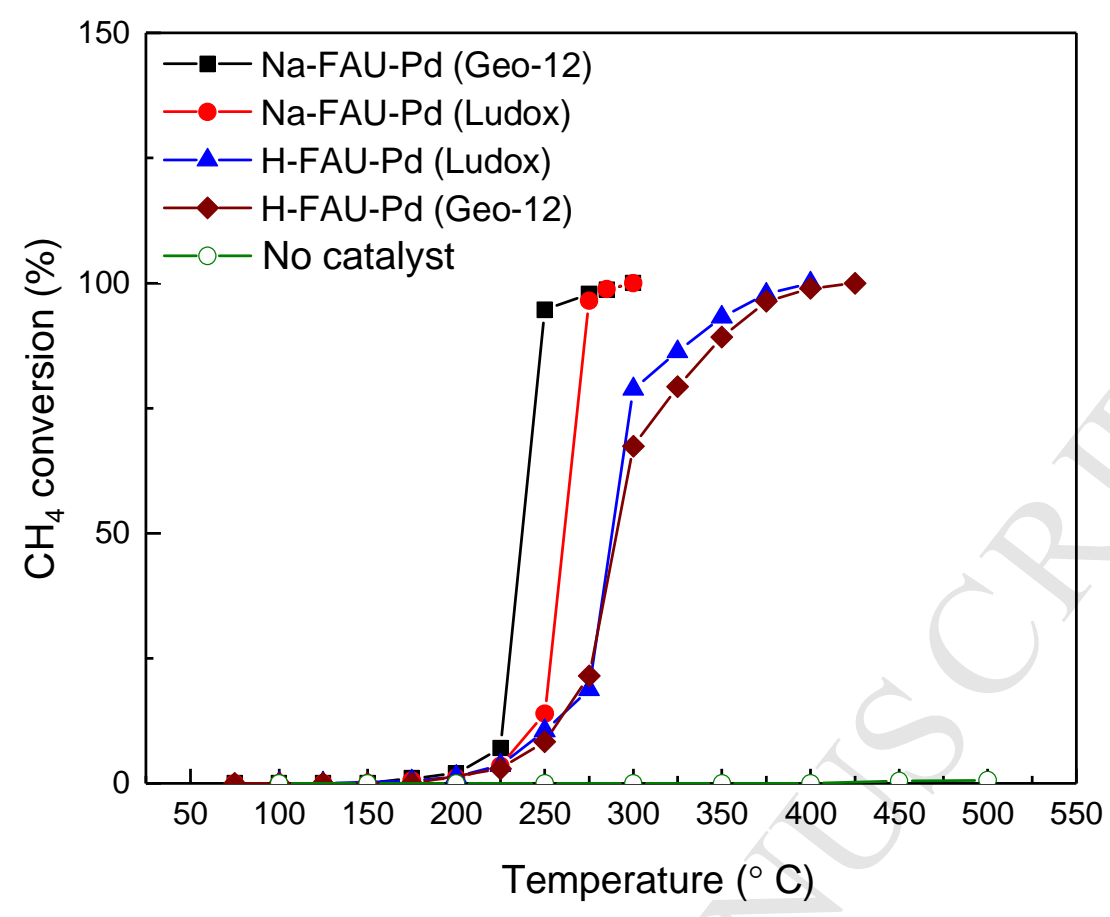

Fig. 5: $\mathrm{CH}_{4}$ conversion vs. reaction temperature over fixed bed reactor. 


\section{Highlights}

First report of zeolite prepared using geothermal fluid extract.

Active in the oxidative decomposition of methane in simulated engine exhaust.

Structural characteristics and catalytic activity comparable to reference sample. 